\title{
Research Article \\ Effects of Digital Filtering in Data Processing of Seismic Acceleration Records
}

\author{
Guergana Mollova \\ Department of Computer-Aided Engineering, University of Architecture, Civil Engineering and Geodesy, 1046 Sofia, Bulgaria
}

Received 12 April 2006; Revised 8 August 2006; Accepted 24 November 2006

Recommended by Liang-Gee Chen

The paper presents an application of digital filtering in data processing of acceleration records from earthquakes. Butterworth, Chebyshev, and Bessel filters with different orders are considered to eliminate the frequency noise. A dataset under investigation includes accelerograms from three stations, located in Turkey (Dinar, Izmit, Kusadasi), all working with an analogue type of seismograph SMA-1. Records from near-source stations to the earthquakes (i.e., with a distance to the epicenter less than $20 \mathrm{~km}$ ) with different moment magnitudes $\mathrm{Mw}=3.8,6.4$, and 7.4 have been examined. We have evaluated the influence of the type of digital filter on time series (acceleration, velocity, displacement), on some strong motion parameters (PGA, PGV, PGD, etc.), and on the FAS (Fourier amplitude spectrum) of acceleration. Several 5\%-damped displacement response spectra applying examined filtering techniques with different filter orders have been shown. SeismoSignal software tool has been used during the examples.

Copyright ( 2007 Hindawi Publishing Corporation. All rights reserved.

\section{INTRODUCTION}

This material presents a study on the influence of signal processing techniques (digital filtering) used in data processing of acceleration records from earthquakes.

The recorded raw ground motion signals are always preprocessed by seismologists before any engineering and seismological analysis takes place. Strong-motion data processing has two main objectives to make the data useful for engineering analysis: (1) correction for the response of strongmotion instrument itself (analogue or digital type of instrument can be used) and (2) reduction of random noise in the recorded signals [1]. Different authors and agencies around the world use various steps in data processing. The major three organizations in the United States (USGS, PEER, CSMIP) (USGS (US Geological Survey), PEER (Pacific Earthquake Engineering Research Centre), CSMIP (California Strong-Motion Instrumentation Program)) also use different signal processing techniques to process records. For example, CSMIP realizes several basic steps [2]: (i) baseline correction (described in Section 2), (ii) instrument correction, (iii) high-frequency filtering (Ormsby filter or lowpass Butterworth with 3rd-/4th-order for digital records), (iv) computation of response spectra (for damping values of 0 , $2,5,10$, and $20 \%$ of critical), and (v) high-pass filtering (the most important issue here is the choice of filter corner).
Another investigation is done in the frame of Italian Network ENEA [3]. A comparison between corrected acceleration for Campano-Lucano earthquake (Italy, 23/11/1980) using time-domain FIR (Ormsby filter), IIR (elliptic filter), and frequency-domain FIR (FFT windows half-cosine smoothed in the transition band) is given there, using alternatively time-domain FIR (Ormsby filter), IIR (elliptic filter), and frequency-domain FIR (FFT windows half-cosine smoothed in the transition band). Other European countries also report about the specific data processing steps adopted by them [4].

A number of recent papers consider the problem of application of different causal and acausal filters for processing of strong-motion data. Boore and Akkar [5] examine the effect of these filtering techniques on time histories, elastic, and inelastic spectra. They found that the response spectra (both elastic and inelastic) computed from causally filtered accelerations can be sensitive to the choice of filter corner periods even for oscillator periods much shorter than the filter corner periods. From the other hand, causal filters do not require pre-event pads (as acausal) to maintain compatibility between the acceleration, velocity, and displacement [5-7], but they can produce significant phase distortions. As a result, considerable differences in the waveforms of displacement (with causal filters) could be observed. Bazzurro et al. [8] investigate causal Butterworth low-and high-pass 
4-pole filters (currently used by PEER), cascade acausal Butterworth 2-pole/2-pole filter (to emulate current USGS processing), and acausal Butterworth 4-pole filter (used by CSMIP). The effect of the filter order and high-pass corner frequency for some real records has been evaluated as well. A new method for nonlinear filtering based on the wavelet transform is introduced in [9]. Further, the proposed approach is compared to two 4th-order linear filter banks (Butterworth and elliptic filters) using the synthetic and real earthquake database.

Another specific application of digital filters concerns seismic acquisition systems. The high performance of modern digital seismic systems (Quanterra, MARS88, RefTek, STL, Titan) is commonly obtained by the use of oversampling and decimation techniques. In order not to violate the sampling theorem, each digital sampling rate reduction must include a digital antialias filter [10]. To achieve maximum resolution during oversampling, the filters must be maximally steep. In addition, they should be stable and cause no distortion of the input signal, at least not within the filter's passband. This requires linear-phase filters which are passing signals without phase changes, causing only a constant time shift. Digital antialias filters are generally implemented as zero-phase FIR filters [10]. From practical point of view it is important to know that they can "generate" precursory signals to impulsive seismic arrivals because of their symmetrical impulse response. These artifacts lead to the severe problems for the determination of onset times and onset polarities (i.e., they can be easily misinterpreted as seismic signals). Different methods to suppress them have been reported (e.g., the zero-phase filter can be changed into a minimum-phase one, prior to any analysis of onset polarities).

There are a lot of software packages used in the field of digital seismology. One good example is SeismoSignal [11]. This program gives an easy and efficient way to process strong-motion data and the capability of deriving a number of strong-motion parameters often required by seismologists and earthquake engineers. We have decided to use this program to set different filter configurations and to evaluate the obtained strong-motion parameters. PREPROC [12] is another package, designed to assist seismologists in preprocessing data in some standard way prior to analysis (socalled cleaning of raw digital data-removing glitches and dropouts), to simulate standard and user-defined instruments and to generate synthetic seismograms for selected earthquakes. In its early development, PREPROC was closely linked to the program PITSA [10]. PITSA contains numerous tools for digital signal processing and routine analysis: filtering functions (Butterworth, Gaussian bandpass, notch filters, etc.), estimation of earthquake magnitude, baseline correction, instrument correction, simulation of arbitrary instruments characteristics, and so forth. The USGS develops own software package BAP [13] to process strong-motion earthquake records. BAP calculates velocity and displacement from the input acceleration, makes linear baseline correction, applies instrument correction, filters high-frequency and/or low-frequency content from the time series, calculates the Fourier amplitude spectrum (FAS), and determines the response spectra.

\section{DATA CORRECTION AND FILTERING}

We follow data correction steps proposed by Zaré and Bard [14]. According to this procedure, a threshold level of 3 $(\sim 10 \mathrm{~dB})$ for the normalized signal-to-noise ratio (SNR) is selected

$$
R_{s n}(f)=\frac{S(f) / \sqrt{t_{s}}}{N(f) / \sqrt{t_{n}}} \geq 3 \quad \forall f \in\left[f_{p 1}, f_{p 2}\right]
$$

Here, $S(f)$ and $N(f)$ are Fourier transforms of the signal and noise, calculated over lengths $t_{s}$ and $t_{n}$, respectively. The same authors propose a catalogue of accelerometric data of Turkey which includes frequency edges $f_{p 1}$ and $f_{p 2}$ for the records from different stations, computed according to the above procedure. It is proved [14] that in the band $\left[f_{p 1}, f_{p 2}\right]$ the information from the records is meaningful and a bandpass filter should be applied to eliminate the frequency noise. A Butterworth bandpass filter of order 2 is applied there. In other words, the appropriate frequency band for each record is calculated on the basis of the ratio of FAS of appropriately selected signal and noise windows. Then, the resulting FAS is compared with the theoretical shape of the far-field FAS of acceleration.

The band $\left[f_{p 1}, f_{p 2}\right]$ is also known as usable data bandwidth (UDB). The UDB gives the frequency or period range within which the data can be used for seismological and earthquake engineering applications. Outside this band, the bandpass filter should remove as much as possible because of noise contamination [2]. Rinaldis [3] also reports about the usefulness of application of SNR procedure to extract frequency edges of bandpass filter.

We have decided to vary with different types of causal bandpass filters (not only Butterworth of order 2) and to evaluate the resulting effect on time series (acceleration, velocity, displacement), on the strong-motion parameters, and on the FAS of acceleration.

The dataset under our investigation includes accelerograms from three stations in Turkey (Dinar, Izmit, $\mathrm{Ku}-$ sadasi), all working with analogue type of seismograph SMA1 (Kinemetrics). Information for the stations and corresponding earthquakes is given in Table 1 (extracted from the catalogue of the accelerometric data of Turkey [14]). We choose to examine only records from near-source stations to the earthquakes (i.e., with a distance to the epicenter less than $20 \mathrm{~km}$ ) with different moment magnitudes Mw of earthquakes, namely, $\mathrm{Mw}=3.8,6.4$, and 7.4. The last two earthquakes are known as Dinar earthquake of October 1, $1995(\mathrm{Mw}=6.4)$ and Kocaeli earthquake of August 17, 1999 $(\mathrm{Mw}=7.4)$.

As it was mentioned above, we choose only stations with analogue recorders SMA-1, in which the acceleration trace on paper or film is digitized. For analogue records, a noise model depends, mainly, on the characteristic of the digitazion equipment [15]. These acceleration data from 
TABLE 1: Stations and data under investigation.

\begin{tabular}{|c|c|c|c|c|c|c|c|}
\hline Station & Coordinates of station & $f_{p 1}[\mathrm{~Hz}]$ & $f_{p 2}[\mathrm{~Hz}]$ & Earthquake (date) & $\begin{array}{l}\text { Coordinates } \\
\text { of epicenter }\end{array}$ & Mw & $\begin{array}{l}\text { Distance to the } \\
\text { epicenter [ Km] }\end{array}$ \\
\hline \multirow{2}{*}{ DIN Dinar Meteo } & $38.06 \mathrm{~N}$ & \multirow{2}{*}{0.2} & \multirow{2}{*}{20} & \multirow{2}{*}{ 01/10/1995 } & $38.11 \mathrm{~N}$ & \multirow{2}{*}{6.4} & \multirow{2}{*}{10} \\
\hline & $30.15 \mathrm{E}$ & & & & $30.05 \mathrm{E}$ & & \\
\hline \multirow{2}{*}{ IZT Izmit Meteo } & $40.79 \mathrm{~N}$ & \multirow{2}{*}{0.12} & \multirow{2}{*}{20} & \multirow{2}{*}{$17 / 08 / 1999$} & $40.70 \mathrm{~N}$ & \multirow{2}{*}{7.4} & \multirow{2}{*}{13} \\
\hline & $29.96 \mathrm{E}$ & & & & $29.91 \mathrm{E}$ & & \\
\hline \multirow{2}{*}{ KUS Kusadasi Meteo } & $37.86 \mathrm{~N}$ & \multirow{2}{*}{3.5} & \multirow{2}{*}{18} & \multirow{2}{*}{ 29/05/1997 } & $37.89 \mathrm{~N}$ & \multirow{2}{*}{3.8} & \multirow{2}{*}{7} \\
\hline & $27.26 \mathrm{E}$ & & & & $27.31 \mathrm{E}$ & & \\
\hline
\end{tabular}

TABLE 2: Parameters of uncorrected acceleration records and baseline correction coefficients.

\begin{tabular}{|c|c|c|c|c|c|}
\hline \multirow{2}{*}{ Station } & \multirow{2}{*}{ Components } & \multirow{2}{*}{ PGA $\left(\mathrm{m} / \mathrm{s}^{2}\right)$} & \multirow{2}{*}{ Number of data } & \multicolumn{2}{|c|}{ Baseline correction $y=a_{0}+a_{1} x$} \\
\hline & & & & $a_{0}$ & $a_{1}$ \\
\hline \multirow{3}{*}{ Dinar } & NS & 2.816282 & 5599 & $-6.16367 \cdot 10^{-2}$ & $3.82333 \cdot 10^{-6}$ \\
\hline & EW & 3.297235 & 5593 & $-5.76997 \cdot 10^{-2}$ & $-1.23158 \cdot 10^{-5}$ \\
\hline & $\mathrm{V}$ & 1.506781 & 5595 & $-5.34008 \cdot 10^{-2}$ & $1.73586 \cdot 10^{-6}$ \\
\hline \multirow{3}{*}{ Izmit } & NS & 1.711672 & 10398 & $-1.78769 \cdot 10^{-2}$ & $1.09724 \cdot 10^{-6}$ \\
\hline & EW & 2.249119 & 10391 & $-1.37701 \cdot 10^{-2}$ & $-5.69802 \cdot 10^{-6}$ \\
\hline & $\mathrm{V}$ & 1.463919 & 10397 & $-1.77262 \cdot 10^{-2}$ & $2.02909 \cdot 10^{-6}$ \\
\hline \multirow{3}{*}{ Kusadasi } & NS & 0.214332 & 1244 & $-6.69740 \cdot 10^{-4}$ & $7.84655 \cdot 10^{-5}$ \\
\hline & EW & 0.212107 & 1241 & $-4.32803 \cdot 10^{-3}$ & $5.95435 \cdot 10^{-5}$ \\
\hline & $\mathrm{V}$ & 0.188608 & 1246 & $-1.18139 \cdot 10^{-3}$ & $-3.68099 \cdot 10^{-5}$ \\
\hline
\end{tabular}

digital equipment have been downloaded ${ }^{1}$ (in raw format with no instrument correction or other processing). Full dataset in our case includes 9 files, or 3 files per North-South (NS), East-West (EW), and Vertical (V) components for each record. The PGA (peak ground acceleration) and the number of data with a time step of 0.005 second for the uncorrected records are shown in Table 2 . The coefficients of linear baseline correction are also given there. As can be seen, the longest is Izmit record.

Baseline correction, as implemented in SeismoSignal [11], consists in (i) determining through regression analysis (least squares fit method), the polynomial curve that best fits the time-acceleration pairs of values and then (ii) subtracting from the actual acceleration values their corresponding counterparts as obtained with the regression-derived equation. The aim of baseline correction [16] is to remove all spurious baseline trends, usually noticeable in the displacement time history, obtained from double-time integration of uncorrected acceleration records. Polynomials of up to the third degree can be employed for this purpose. We use a linear baseline correction $y=a_{0}+a_{1} x$ (as accepted in [11]) and do not examine here the role of this processing technique.

For our investigation we apply bandpass filters with different orders $N$ designed by Butterworth, Chebyshev (type I), and Bessel approximation methods. Butterworth filters

\footnotetext{
${ }^{1}$ Accelerograms (raw records) obtained through the National StrongMotion Network of Turkey http://angora.deprem.gov.tr
}

have a maximally flat response in the passband but at the cost of smaller roll-off slope (in comparison to a Chebyshev filter of the same order). The later, however, can be easily overcome by the use of a higher order filter. In the case of Chebyshev-type I approximation, we obtain an equiripple amplitude characteristic in the passband. In our examples we are interested in how the value of the ripple in the passband will affect strong-motion parameters. When compared to their Butterworth and Chebyshev counterparts, Bessel filters produce the slowest frequency roll-off and require the highest order to meet an attenuation specification. In addition, all causal IIR filters cause time-delay distortion in the filtered signal (usually measured by group delay).

We investigate how the choice of the digital filter influences the following strong-motion parameters, calculated using SeismoSignal:

(i) peak ground acceleration: PGA $=\max |a(t)|$;

(ii) peak ground velocity: $\mathrm{PGV}=\max |v(t)|$;

(iii) peak ground displacement: $\mathrm{PGD}=\max |d(t)|$;

(iv) Arias intensity:

$$
I_{a}=\frac{\pi}{2 g} \int_{0}^{t r}[a(t)]^{2} d t
$$

(v) predominant period TP: period at which the maximum spectral acceleration occurs in acceleration response spectrum, calculated at 5\% damping; 

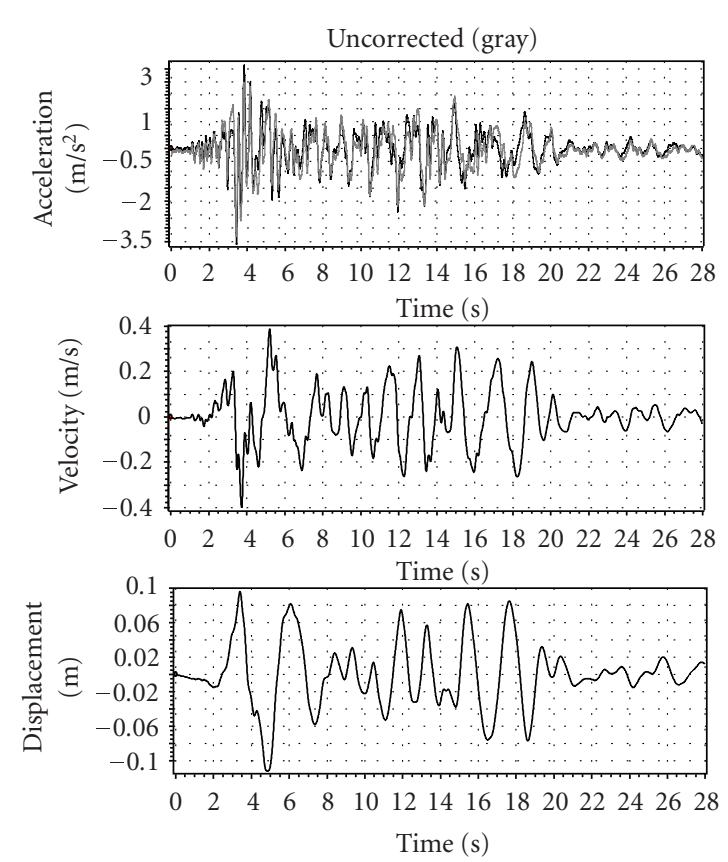

(a) Butterworth
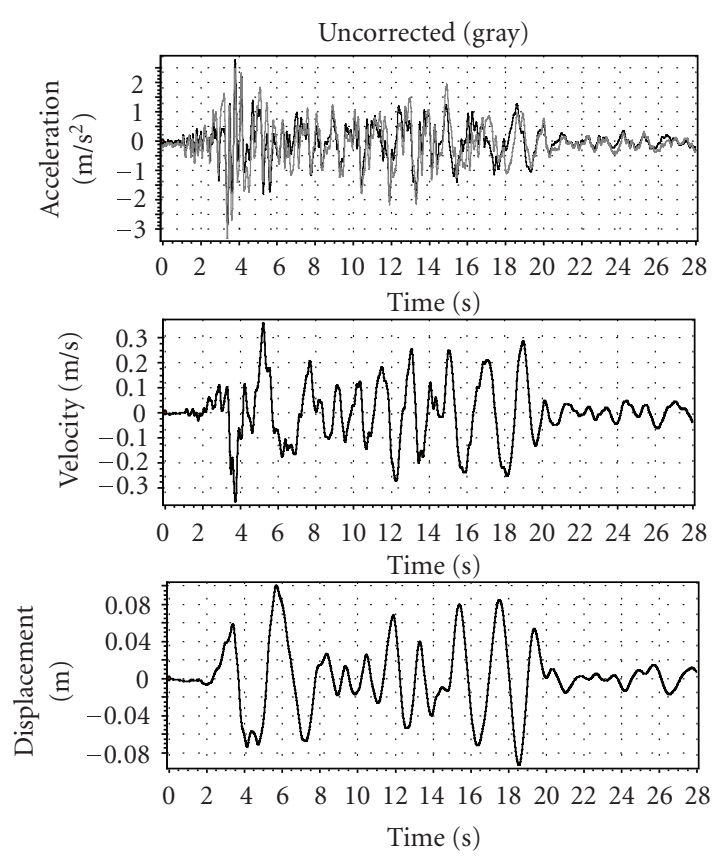

(b) Chebysher (3dB)
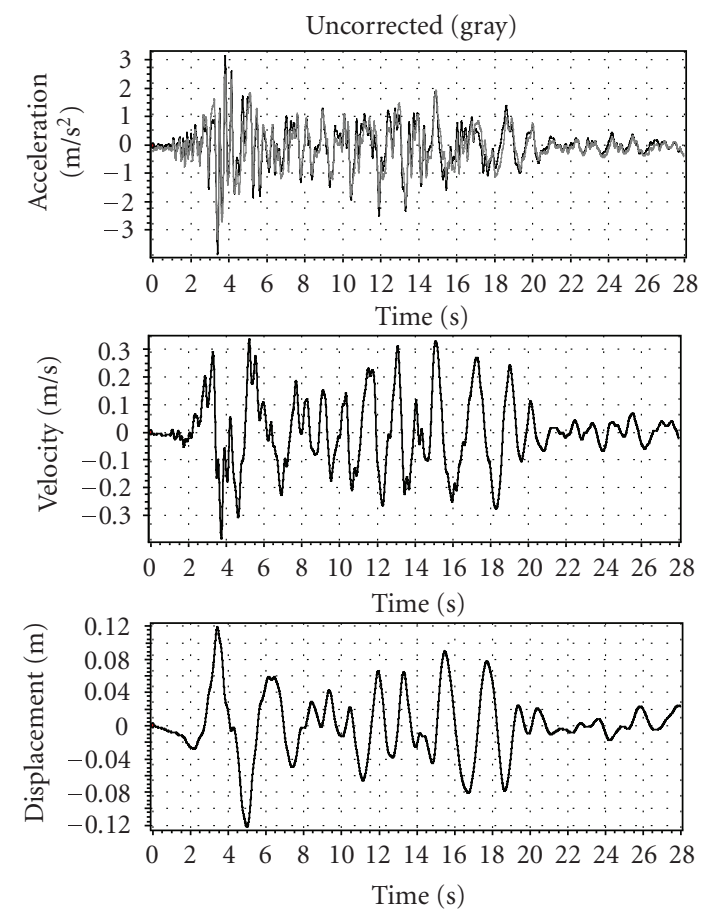

(c) Bessel

FIGURE 1: Corrected Dinar acceleration, velocity, and displacement (EW component) using bandpass filter: $N=4, f_{p 1}=0.2 \mathrm{~Hz}, f_{p 2}=20 \mathrm{~Hz}$.

(vi) significant duration TD: the interval of time over which a proportion (percentage) of the total $I_{a}$ is accumulated (by default: the interval between the $5 \%$ and $95 \%$ thresholds).

The parameter $t_{r}$ in (2) denotes the total seismic duration, $g$ is the acceleration of gravity.

\section{ANALYSIS OF RESULTS AND CONCLUSIONS}

After definition of accelerograms, the corresponding velocity and displacement time histories are obtained in SeismoSignal (through single and double time-integration, resp.). We examine the resulting time histories when the acceleration 


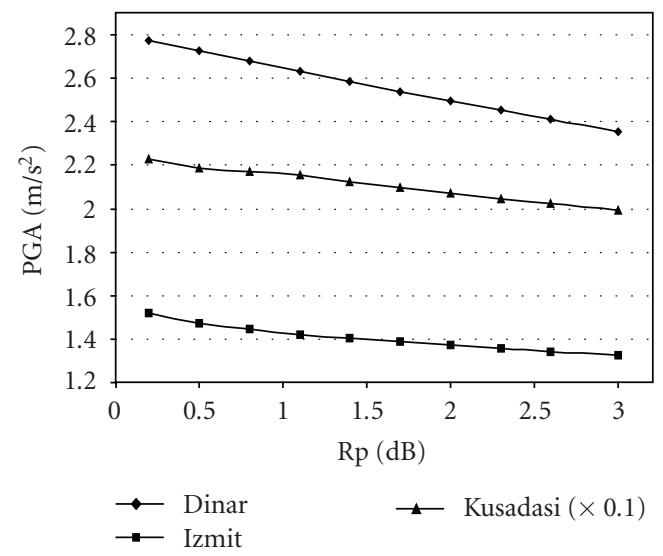

(a)

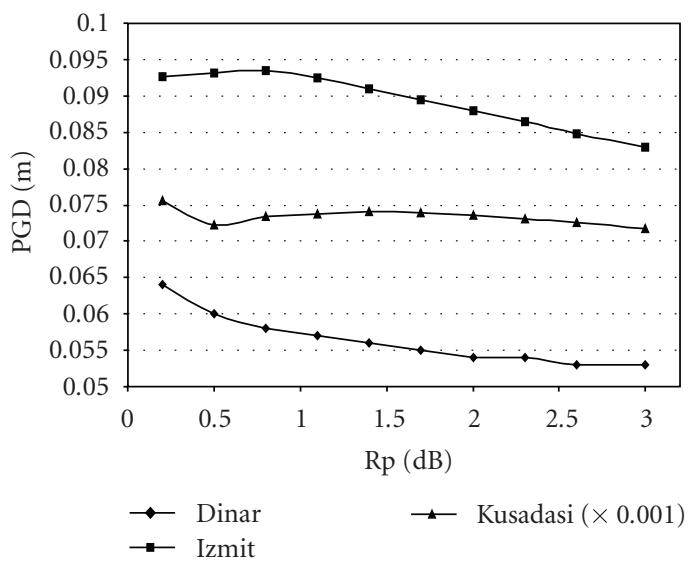

(c)

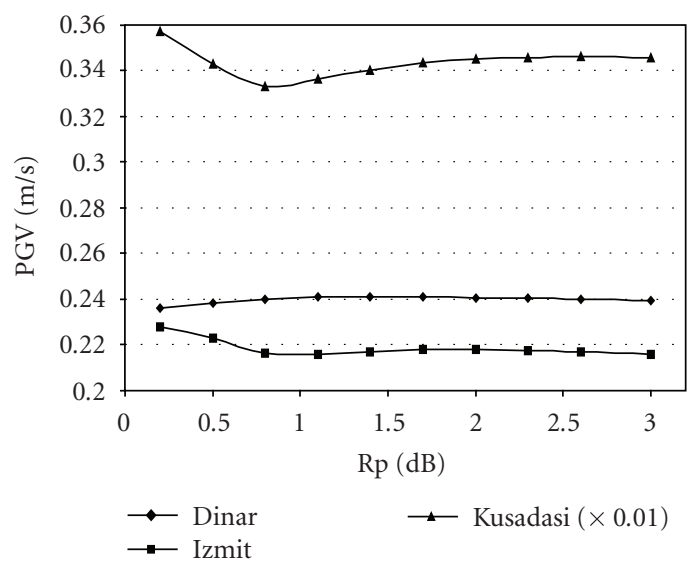

(b)

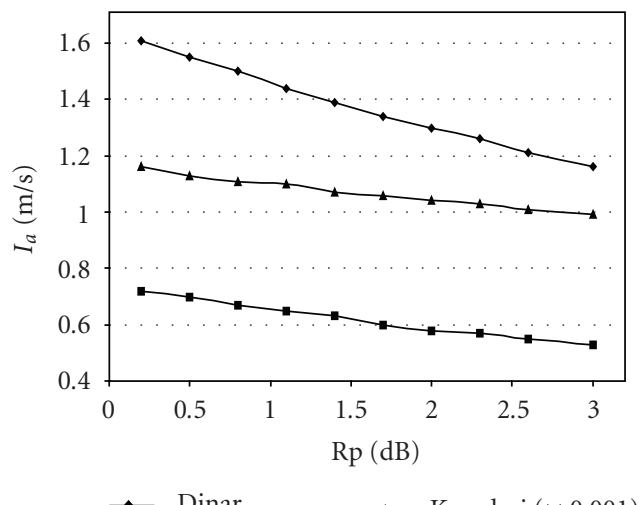

$\rightarrow$ Dinar

$\neg$ Kusadasi $(\times 0.001)$

(d)

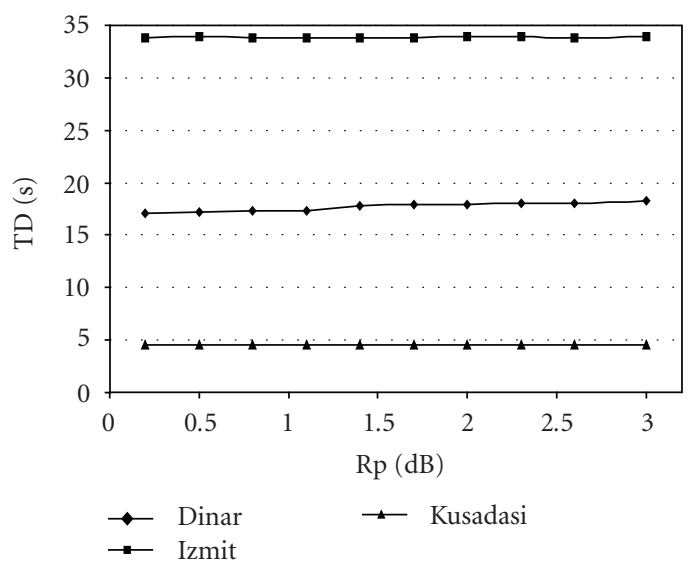

(e)

FIGURE 2: Strong-motion parameters as a function of the passband ripple Rp [dB] (NS component). Note: different scales for Kusadasi record.

records are bandpass filtered with orders $N=2,4,6$ (and $N=8$ for the weakest earthquake with $\mathrm{Mw}=3.8$ ). Examples have shown that only these filters orders could be applied (under given corner frequency conditions from Table 1). For higher orders the waveforms of the corrected time histories are abnormally different compared to the uncorrected ones. Corrected time series for Dinar station (EW component) with 4th-order Butterworth, Chebyshev, and Bessel filters 

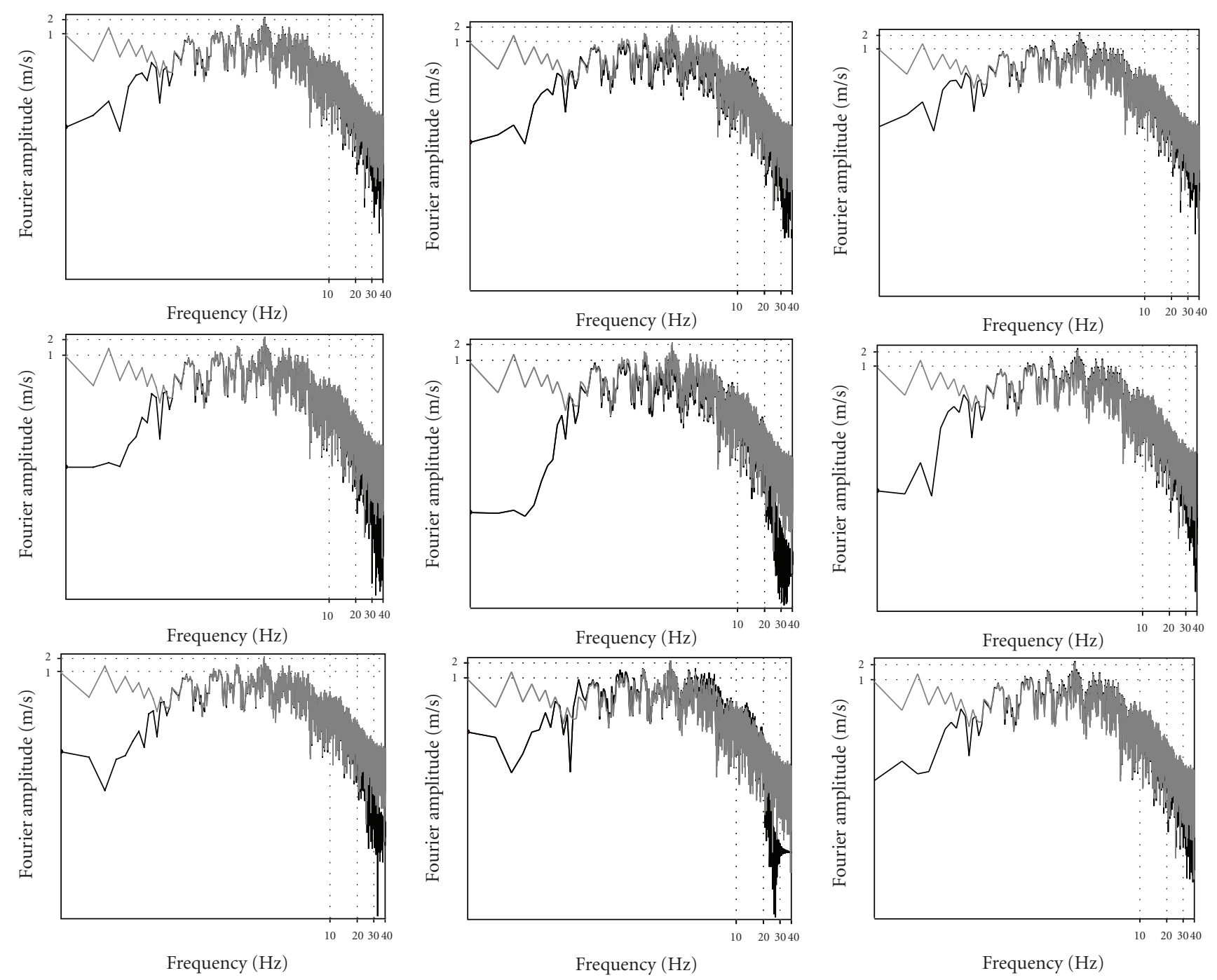

(a) Butterworth

(b) Chebyshev (3 dB)

(c) Bessel

FIGURE 3: Fourier spectra of acceleration for bandpass filtered Izmit record between $0.12 \mathrm{~Hz}$ and $20 \mathrm{~Hz}$ for orders $N=2,4$, and 6 (from up to down) NS component. Note: the graphics in gray color show the uncorrected records.

$\left(f_{p 1}=0.2 \mathrm{~Hz}, f_{p 2}=20 \mathrm{~Hz}\right)$ are shown in Figures $1(\mathrm{a}), 1(\mathrm{~b})$, $1(\mathrm{c})$, respectively. It is obvious that in all cases corrected acceleration is affected by the time shift (due to the application of causal IIR filters).

We have obtained the numerical values of the examined strong-motion parameters for Butterworth, Chebyshev, or Bessel processed records using filters from different orders (not shown here). The only parameter which does not depend on the choice of the filter is TP.

Figure 2 shows the influence of the Chebyshev passband ripple $\mathrm{Rp}[\mathrm{dB}]$ on the NS component of Dinar, Izmit, and Kusadasi records (for $N=4$ ). Different examinations varying $\mathrm{Rp}$ in the range from 0.2 to $3 \mathrm{~dB}$ have been made. The predominant period TP is a constant value in the above range and does not depend on Rp. Significant duration TD is almost constant too (see the last graphic of Figure 2). However, the peak values of processed time series and Arias intensity $I_{a}$ depend significantly on the variation of Rp (it is valid for all station records). We have found that PGA decreases substantially (with up to $15-20 \%$ ) with increasing Rp. The PGA is one of the main parameters of interest for engineering application. As we have expected, values of all parameters for $\mathrm{Rp}=$ $0.2 \mathrm{~dB}$ are the closest to the values obtained with Butterworth 4th-order filter (i.e., maximally flat passband case).

Figure 3 presents the results for FAS of acceleration for bandpass filtered Izmit record between $0.12 \mathrm{~Hz}$ and $20 \mathrm{~Hz}$ for orders $N=2,4$, and 6 (NS component). The FAS and the power spectrum (or power spectral density function) are computed in SeismoSignal by means of fast Fourier transformation (FFT) of the input time history. The Fourier spectra show how the amplitude of the ground motion is distributed with respect to frequency (or period), effectively meaning 

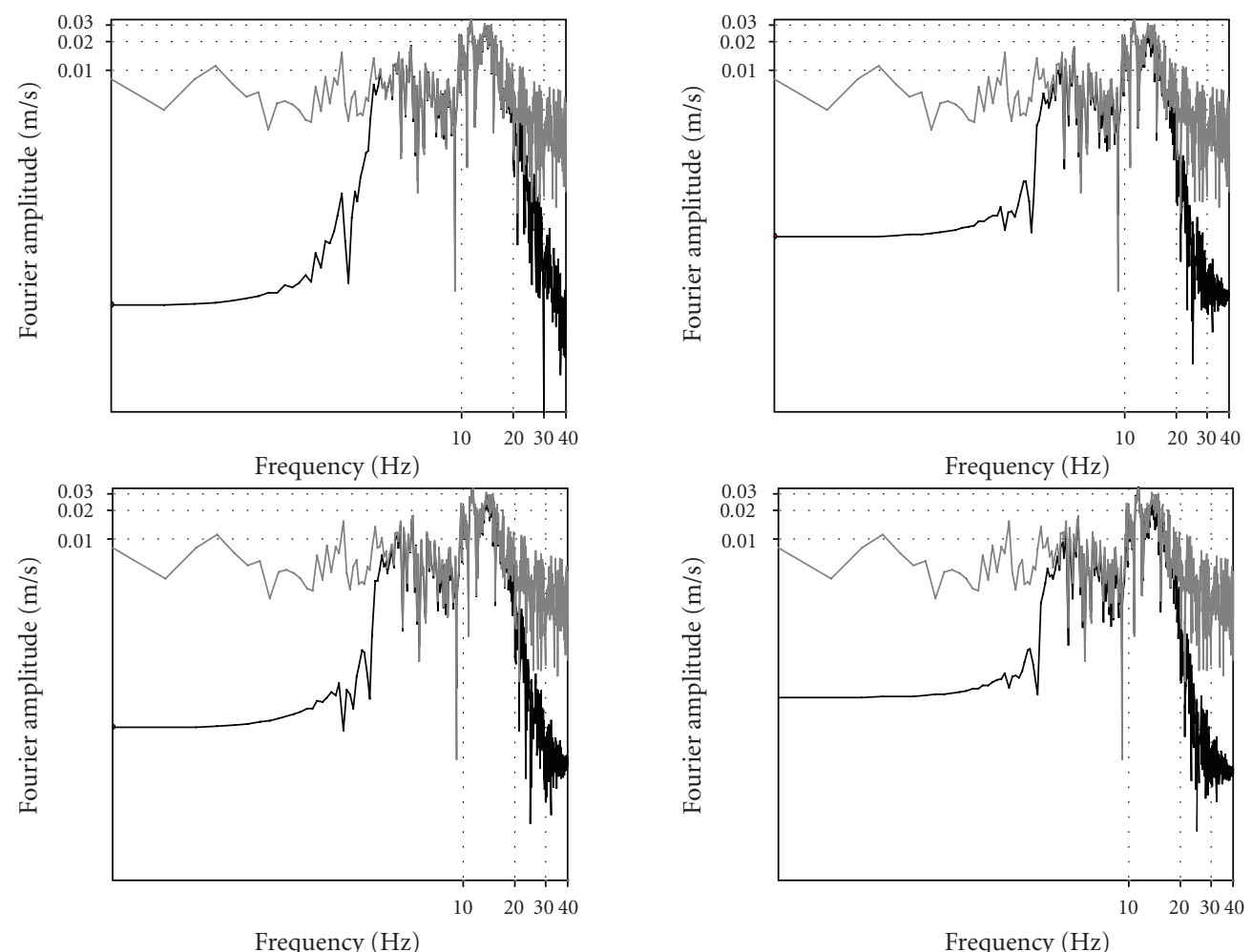

(a)
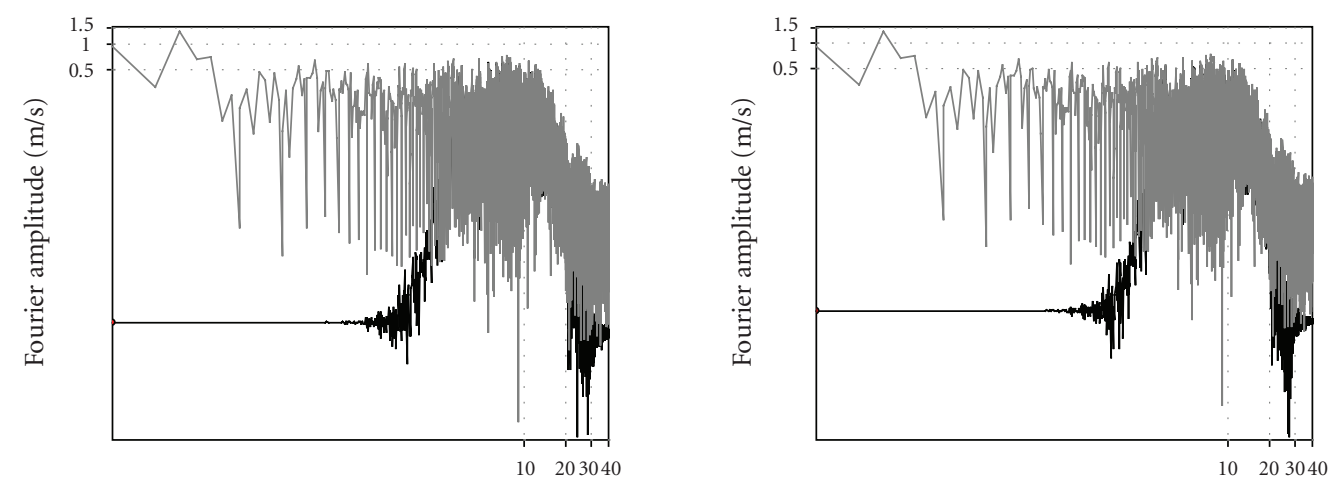

Frequency $(\mathrm{Hz})$

Frequency $(\mathrm{Hz})$

(b)

FIgURE 4: (a) Fourier spectra of acceleration for bandpass Chebyshev filtered Kusadasi record between $3.5 \mathrm{~Hz}$ and $18 \mathrm{~Hz}$ for $\mathrm{N}=4$, $\mathrm{V}$ component with $\mathrm{Rp}=0.2 \mathrm{~dB}$ and $1.1 \mathrm{~dB}$ (left column), and $\mathrm{Rp}=2 \mathrm{~dB}$ and $3 \mathrm{~dB}$ (right column). Note: the graphics in gray color show the uncorrected records. (b) Fourier spectra of acceleration for bandpass Chebyshev filtered Izmit record between $0.12 \mathrm{~Hz}$ and $20 \mathrm{~Hz}$ for $\mathrm{N}=4$, $\mathrm{V}$ component with $\mathrm{Rp}=1.2 \mathrm{~dB}$ (left) and $3 \mathrm{~dB}$ (right). Note: the graphics in gray color show the uncorrected records.

that the frequency content of the given accelerogram can be fully determined.

As explained in [14], a more or less constant amplitude of the FFT spectrum at frequencies lower than $f_{p 1}$ or at frequencies beyond $f_{p 2}$ is generally an indication of large low- or high-frequency noise, respectively. We can see in Figure 3 that the parts of the FAS (uncorrected) below $0.12 \mathrm{~Hz}$ and beyond $20 \mathrm{~Hz}$ are abnormally high. This proves the necessity of application of bandpass filter with the above frequency edges regarding low-and high-frequency noise suppression.

Graphical results for FAS confirm that all filter orders examined could be used except Chebyshev 6th-order filter. As a best choice we recommend order $N=4$ for all stations. Of course, we should bear in mind the phase distortion caused by IIR filters. Furthermore, we have proved that the change of the ripple $\mathrm{Rp}$ (Chebyshev filter) has a small influence on the obtained FAS (Figures 4(a), 4(b)). 


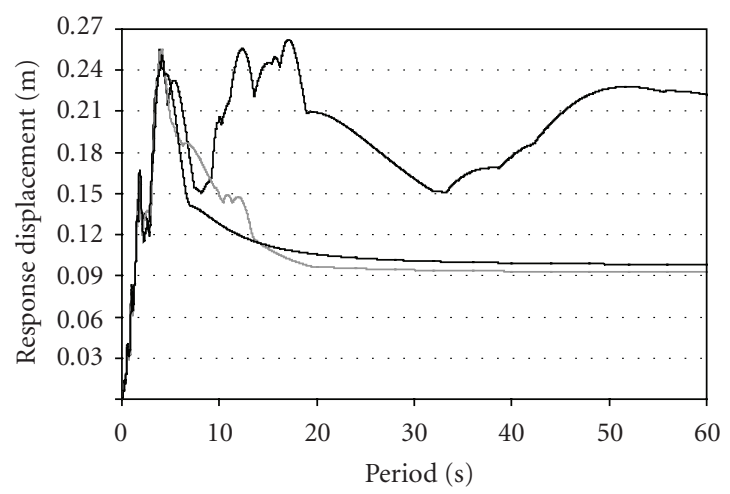

$\begin{aligned}-N & =2 \text { (upper plot) } \\ -N & =4 \text { (in gray color) }\end{aligned}$

(a)

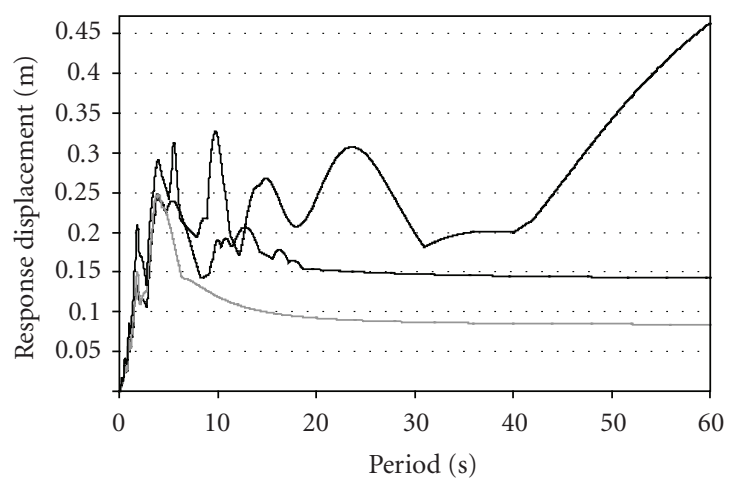

$\begin{aligned}-N & =2(\text { lower plot) } \\ N & =4 \text { (in gray color) }\end{aligned}$

(b)

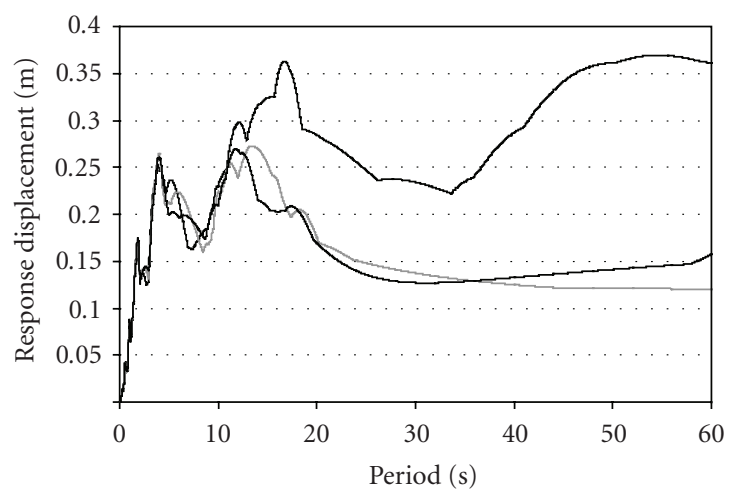

$\begin{aligned}-N & =2(\text { upper plot }) \\ N & =4 \text { (in gray color) }\end{aligned} \quad-N=6$ (lower plot)

(c)

Figure 5: Displacement response spectra for bandpass filtered Izmit record, NS component, using (a) Butterworth, (b) Chebyshev (3 dB), (c) Bessel filters.
Finally, the 5\%-damped displacement response spectra (SD) for Izmit record (NS component) have been computed (Figures 5(a), 5(b)), 5(c), applying different filtering techniques and filter orders. The evaluation is done for periods between 0.02 second and 60 seconds with a period step of 0.02 second. The graphical results from Figure 5 correspond to these ones from Figure 3 (Fourier spectra for Izmit record filtered with the same edge frequencies). As could be seen, changing the filter order (between two and four/or between two and six) influences the smaller SD. The only exception is Chebyshev filter with order $N=6$ (Figure 5(b)) which reflects larger values of SD.

We would like finally to emphasize that all investigations in this study are carried out using chosen filtering techniques (Butterworth, Chebyshev-type I, or Bessel methods) and under given parameters (order, edge frequencies, and passband ripple for Chebyshev filter). The obtained numerical and graphical results may not be relevant when other filtering techniques or parameters are applied.

\section{ACKNOWLEDGMENTS}

This work is supported by the Alexander von Humboldt Foundation (Project BUL 1059420). The author would like also to thank all anonymous reviewers for their useful recommendations and remarks.

\section{REFERENCES}

[1] B. Darragh, W. Silva, and N. Gregor, "Strong motion record processing for the PEER centre," in Proceedings of COSMOS Invited Workshop on Strong-Motion Record Processing, Richmond, Calif, USA, May 2004, http://www.cosmos-eq.org/ recordProcessingPapers.html.

[2] A. F. Shakal, M. J. Huang, and V. M. Graizer, "CSMIP strong-motion data processing," in Proceedings of COSMOS Invited Workshop on Strong-Motion Record Processing, Richmond, Calif, USA, May 2004, http://www.cosmos-eq.org/ recordProcessingPapers.html.

[3] D. Rinaldis, "Aquisition and processing of analogue and digital accelerometric records: ENEA methodology and experience from Italian earthquakes," in Proceedings of COSMOS Invited Workshop on Strong-Motion Record Processing, Richmond, Calif, USA, May 2004, http://www.cosmos-eq.org/ recordProcessingPapers.html.

[4] "Internet Site of the European Strong-Motion Database," http://www.isesd.cv.ic.ac.uk.

[5] D. M. Boore and S. Akkar, "Effect of causal and acausal filters on elastic and inelastic response spectra," Earthquake Engineering and Structural Dynamics, vol. 32, no. 11, pp. 17291748, 2003.

[6] D. M. Boore, "On pads and filters: processing strong-motion data," Bulletin of the Seismological Society of America, vol. 95, no. 2, pp. 745-750, 2005.

[7] D. M. Boore and J. J. Bommer, "Processing of strong-motion accelerograms: needs, options and consequences," Soil Dynamics and Earthquake Engineering, vol. 25, no. 2, pp. 93-115, 2005. 
[8] P. Bazzurro, B. Sjoberg, N. Luco, W. Silva, and R. Darragh, "Effects of strong motion processing procedures on time histories, elastic and inelastic spectra," in Proceedings of COSMOS Invited Workshop on Strong-Motion Record Processing, Richmond, Calif, USA, May 2004, http://www.cosmos-eq.org/ recordProcessingPapers.html.

[9] A. Pazos, M. J. González, and G. Alguacil, "Non-linear filter, using the wavelet transform, applied to seismological records," Journal of Seismology, vol. 7, no. 4, pp. 413-429, 2003.

[10] F. Scherbaum, Of Poles and Zeros: Fundamentals of Digital Seismology, Kluwer Academic, Dordrecht, The Netherlands, 2nd edition, 2000.

[11] "SeismoSignal - a computer program for signal processing of strong-motion data," 2004, ver.3.1.0, http://www.seismosoft .com.

[12] A. Plesinger, M. Zmeskal, and J. Zednik, Automated Preprocessing of Digital Seismograms - Principles and Software, PragueGolden, Prague, Czech Republic, 1996.

[13] A. M. Converse and A. G. Brady, "BAP: basic strong-motion accelerogram processing software; ver.1.0," Open-File Report 92-296A, p. 178, U.S. Geological Survey, Denver, Colo, USA, 1992.

[14] M. Zaré and P.-Y. Bard, "Strong motion dataset of Turkey: data processing and site classification," Soil Dynamics and Earthquake Engineering, vol. 22, no. 8, pp. 703-718, 2002.

[15] D. Rinaldis, J. M. H. Menu, and X. Goula, "A study of various uncorrected versions of the same ground acceleration signal," in Proceedings of the 8th European Conference on Earthquake Engineering (ECEE '86), vol. 7, pp. 1-8, Lisbon, Portugal, September 1986.

[16] D. M. Boore, "Effect of baseline corrections on displacements and response spectra for several recordings of the 1999 ChiChi, Taiwan, earthquake," Bulletin of the Seismological Society of America, vol. 91, no. 5, pp. 1199-1211, 2001.

Guergana Mollova received the M.S. and Ph.D. degrees both in electronics from the Technical University of Sofia, Bulgaria. Since 1992, she is with the Department of Computer-Aided Engineering of the University of Architecture, Civil Engineering and Geodesy of Sofia, where she is currently an Associate Professor. Her main research area is digital signal processing theory and methods, including the least-squares ap-

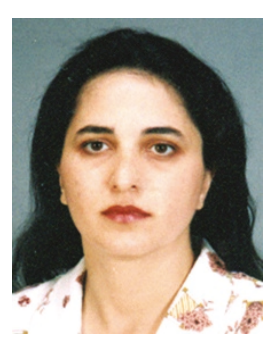
proach for one- and multidimensional digital filters, digital differentiators, and Hilbert transformers. During the last years her research interests are focused on application aspects of digital filtering techniques for analysis of data records from strong-motion earthquakes. She is Senior Member of IEEE and also Member of several national professional organizations. She is a recipient of the Alexander von Humboldt Foundation Fellowship. 